\title{
Hegemonic masculine conceptualisation in gang culture
}

\author{
Russell Luyt and Don Foster* Department \\ of Psychology, University of Cape Town, Private Bag, \\ Rondebosch, 7701
}

\begin{abstract}
This research sought to investigate the relationship between gang processes and differing forms of masculine expression. Three hundred and sixteen male participants, drawn from secondary schools within Cape Town, were included in the study. These schools were in areas differentially characterised by gang activity. The questionnaire included the newly devised Male Attitude Norm Inventory designed to explore hegemonic conceptualisations of masculinity. Factor analytic procedures rendered a three-factor model stressing the importance of male toughness, success and control. Through a series of t-tests for independent samples, as well as supporting qualitative data, participants from areas characterised by high gang activity were found to support these hegemonic elements to a significantly greater extent.
\end{abstract}

*To whom correspondence should be addressed

\begin{abstract}
"Die gangsters van vandag is almal jonk en hulle sterf ook jonk. Een van my beste vriende was 'n

'Ghetto Kid' toe het ek nie meer met hom gepraat nie. Saterdag skiet ander gangsters hom dood. En hy was net 18 jaar oud"

(Participant 188: Area B).
\end{abstract}

'The gangsters of today are all young and they die young as well. One of my best friends was a 'Ghetto Kid', as a result I stopped talking to him. On Saterday he was shot dead by other gangsters. And he was only 18 years old'

(Authors' translation).

This research sought to investigate the relationship between gang activity and diverse forms of masculine expression. As a comparative exercise it attempted to explore differences in masculine performance, between areas either embedded in gang culture or those removed from its everyday occurrence, assessing the impact of omnipresent gang processes on masculine understanding.

Given the pervasive presence of gang activity within particular South African communities (Douglas-Hamilton, 1995; Mamputa, 1991) it seems surprising that so little research has dedicated itself in exploration of this ever-increasing 'problem'. The investigation of masculinity has too remained an undervalued field, having gained increasing currency within the last decade, however continuing to remain restricted to a select academic audience (Connell, 1987, 1995). The present initiative draws these two areas of interest together in a study involving both quantitative and qualitative dimensions. Joe and Chesney- Lind (1995) stress the importance of such an approach by underlining that although gangs are predominantly male driven social formations little research has attempted to understand them from within this frame of reference.

\section{Theorising gang activity}

"Die bendes in ons omgewing is ' $n$ bedreiging vir ons gemeenskap. Mees hoor gereeld van mense wat, gerop word, diestal, beseering en selfs mense wat vermoor word. Soms as jy wil uitgaan moet jy altyd versigtig was oor wat jy aantrek",

(Participant 204: Area B).

'The gangsters in our surroundings are a threat to our community. One hears regularly of people who are robbed, their possessions stolen, are injured and even people that get murdered. Sometimes when you want to go out you always have to be careful about what you wear

(Authors' translation).
Decker and van Winkle (1996) stress that the study of gangs is not a new phenomenon, having taken place for over a century, and note their prevalence in contexts defined by rapid population growth and economic deprivation. In South Africa their activity is said to have intensified largely in response to the chaos and dislocation caused during the Apartheid era (Daba, 1991; Kinnes, 1995). Despite their long history, numerous authors highlight that gang membership in Cape Town burgeoned as a result of the poverty and deprivation caused as a result of discriminatory political projects, specifically forced removal (Pinnock, 1980a, 1980b, 1984; Schärf, 1985). Through gang structures individuals were able to fulfil unmet needs, dreams, and desires otherwise beyond their furthest reach (Pinnock, 1980b). In this sense urban gangs are argued to function as adaptive social formations in environments of great social stress, providing youth with specific socio-economic needs that traditional institutions such as the family are unable to meet (Pinnock, 1997).

This conceptualisation appears in dramatic contrast to theorising that attributes gang activity to either pathological individual, or social factors, predisposing gang members to violent and antisocial behaviour (Decker \& van Winkle, 1996; DouglasHamilton, 1995). These 'psychogenic' approaches fail to take adequate cognisance of structured inequality occurring in society that prompts the development of unique adaptive social formations such as the gang. Rather they encourage essentialist notions surrounding disempowered social groups, implying their innately deviant nature, and as such reinforcing prejudicial assumptions. This understanding proves particularly inappropriate in a South African analysis in which Apartheid policy was itself an exercise in structured inequality, underlining the importance of viewing gang activity as a product of socio-economic design, rather than an outgrowth of psycho-social abnormality.

As an alternative Douglas-Hamilton (1995) notes the utility of 'subcultural theorising' in the exploration of gang formation. It is argued to prove beneficial in highlighting the broader sociostructural milieu in which gang activity takes place, typically suggesting that the occurrence of gangs in predominantly working-class settings may be seen as a consequence of the disempowered position young males find themselves in. These men are believed to construct alternative behavioural patterns that enable them to achieve success normally only available to middle-class males. This approach propagates that all men hold similar values surrounding the importance of success, power and prestige in society. However this explanation ultimately fails as it slides inexorably into the use of normalising judgement, in which working-class behaviours are conceptualised as deviant repertoires of expression, positioning middle-class interactive styles as the 'healthy' norm (Hagedorn, 
1998).

Despite the fact that gangs are predominantly male driven social formations little research attempts to understand them through this logic. Studies that do exist operate from within subcultural theorising, stressing the 'hypermasculine' nature of workingclass men, as such often contrasting them to middle class males who supposedly express 'normal' masculine attributes (Hagedorn, 1998). Collier (1998) stresses that this unitary understanding of masculinity, in which all other expressions are merely viewed as deviations from the norm, has undergone severe criticism from post-structuralist theorists emphasising the significance of exploring crime from within the ambit of multiple masculinities.

\section{The masculinities of subordinate men: Implications for gang research}

\author{
"There are no 'real men' a real man is only as \\ changing and unique as the individuals who might \\ require or earn this label" \\ (Participant 44: Area A).
}

The unitary conceptualisation of masculinity, suggesting the deviancy of all other masculine manifestations that differ from its 'normal' form, is embedded in long established sex role theorising (Wetherell \& Griffin, 1991). Although Connell (1987) stresses that sex role theorising has played a crucial role in subverting essentialist notions of gender difference as biologically innate, rather locating its origin in social expectation, grave flaws appear in the theory that undermines its utility as a means with which to explore masculinity.

Coleman (1990) suggests that the alternative notion of 'doing masculinity' best serves to encompass an understanding of gender as a negotiated social category. This implies its constant reproduction through socially informed behavioural interaction, providing the means by which men and women are able to reaffirm their membership to suitable sex categories. In this sense gender is not located within the individual, as a learnt complex of specific sex roles, but rather situated between them in a ceaseless tide of interaction. Du Pisani (1997) provides an interesting illustration of this, tracing changing ideals in Afrikaner masculinity between 1935 - 1995 .

In essence individuals are seen to involve themselves in gendered activity informed - at each specific moment across time and space - through both their particular contextual positioning as well as their location in broader cultural and ideological structures (Connell, 1995). Carrigan, Connell and Lee (1987) note that although understanding of gender may vary across socio-historical contexts, in which a diverse range of normative behaviours may be adopted as a prerequisite to its accomplishment, it consistently implies particular structured relations of social power. In this regard male gender practice is largely determined through its relationship to the cultural ideal of masculinity, varying over context as a consequence of changing structural features, and re-negotiated in order to maintain existing relations of domination (Connell, 1987). This cultural ideal is well described by:

\footnotetext{
"The concept of hegemonic masculinity (which) provides a way of explaining that though a number of masculinities coexist, a particular version of masculinity holds sway, bestowing power and privilege on men who espouse it and claim it as their own." (Morrell, 1998: 608).
}

In this sense dominant notions of masculinity are a constant collective practice that serve to gain individuals access to power and privilege as well as reinforcing structural relations of domination over women and subordinate masculinities. Importantly its pervasive dominance does not suggest its complete hegemony, as other forms of masculinity continue to find expression, and may at times challenge ascendant conceptualisations (Connell, 1987; Carrigan et al., 1987; Wetherell \& Griffin, 1991). Different notions of masculinity are frequently argued to emerge along class, race and sexuality lines, providing the basis for contestation and change to occur surrounding its meaning (Hearn \& Collinson, 1994). South African history finds itself replete with examples of such contestation. Swart (1998) attributes the 1914 Boer rebellion to a threatened sense of masculine identity amongst Afrikaner males, whilst Hemson (1997) discusses fluid conceptions of masculinity during Apartheid resistance in Kwa-Zulu-Natal.

Thus an understanding of gender as an ongoing social practice supporting and reproducing particular structured relations of power, unlike sex role theorising, accommodates its sociohistorical analysis (Connell, 1987). The notion of locating gender in broader socio-structural relations of power avoids pathologising alternative masculine expression - including the hypermasculine - merely suggesting the contested nature of masculinity. It aids a conceptualisation of individuals as active social agents in the construction and accomplishment of masculinity (Coleman, 1990).

This conceptualisation holds important implications for gang research which despite having explored group processes that overwhelmingly involve men - seen in a plethora of subcultural research - has largely failed to do so from a gender informed perspective (Wetherell \& Griffin, 1991). Here it is argued that the differential construction of masculinity across groups should be seen as a pivotal factor in the genesis of gang activity (Hagedorn, 1998).

Research on gang activity testifies to the fact that the masculine values and behaviours of these men are embedded within broader structural relations of power (Hagedorn, 1998; Joe \& Chesney-Lind, 1995). That is to say working-class males are believed to experience ambiguity between their lived reality and hegemonic societal expectations surrounding manhood (hooks, 1995). Hagedorn (1998) stresses that when 'legitimate' practices serving to validate an individual's masculinity are not possible due to their contextual positioning, alternative behaviour is formulated that matches the values espoused by hegemonic masculinity, providing a means of achieving manliness. Accordingly Connell (1995) argues that exaggerated forms of masculinity frequently develop in these contexts of powerlessness, as overstated rituals of gender appropriate practice, which through their collective performance lead to the accomplishment of manhood. In essence these behaviours allow working-class males to lay claim to the only arena of power available to them: their dominant status as men.

In this sense gender practice that fails to mirror normative behavioural prescriptions should not be seen as instances of 'protest', in which individuals reject hegemonic values, but rather often reflect an imposed restraint on achieving 'true' masculinity through normative means (Hagedorn, 1998). Pyke (1996) reports that as a result of their subordinated status, working class males - including urban gangs - re-negotiate their position in a positive fashion. Within this re-negotiation they are argued to adopt masculine qualities readily available in the contexts they inhabit, often associated with their material conditions of life, such as the need for physical toughness. 
Messerschmidt (1997) stresses that gangs provide an ideal arena in which working-class boys are able to deal with their experience of structured powerlessness. Research indicates that the all-male gang environment encourages the use of

'hypermasculinity' as a base on which threatened self-esteem may be bolstered. It is highlighted that single-sex peer groups such as the gang most strongly contribute to gender identity and attitude formation, particularly in situations in which the family is seen to provide little emotional support (Toch, 1998). Additionally literature indicates that in contexts of male homosociality settings of all-male social interaction - hegemonic values of masculinity are continually reinforced (Bird, 1996).

Thus gang activity may be seen as an integral facet in the lives of many disempowered males, enabling them to collectively display manly attributes not otherwise available, and thereby reinforcing their status as 'true' men in agreement with hegemonic notions of masculinity (Joe and Chesney-Lind,

1995). As such the understanding of gender adopted here avoids suggesting that the often hypermasculine nature of workingclass men reflect a dramatic departure from the supposedly 'normal' expression of masculinity in middle-class settings, rather simply a re-negotiation of the meaning surrounding masculinity.

\section{Summary}

In sum gender theorising, propagating the importance of conceptualising masculinity as a continually re-worked social category in structured relations of power, offers a helpful framework within which to explore its negotiation by individuals in contexts differentially embedded in gang culture. In short this study seeks to investigate the negotiation of masculinity by men in environments either characterised by high or low gang activity. It was believed likely that gang culture stimulates the expression of hypermasculinity as a source of 'manly' validation in disempowered settings. Both quantitative and qualitative methods were employed toward this pursuit, the former providing core material surrounding masculine conceptualisation across groups, whilst the latter rendered data rich in its descriptive utility. In doing so these research methods attempted to account for the unique construction of masculinities across locales in terms of their positioning within varying social contexts.

\section{Method}

\section{Participants}

Purposive sampling was applied in order to locate potential participants in Cape Town for inclusion within the study. The process initially involved the delimitation of areas dissimilarly affected by gang activity through the use of available crime statistics (South African Police Service, 1999). Secondary descriptive statistics presented in Table 1 were derived from this data, together with Census 1996 population figures, and served to illustrate the marked difference in criminal behaviour between two specific areas.
A distinct disparity in gang related criminal activity emerged between these two locales in which criminal behaviour in 'Area B' was approximately double that of 'Area A'. Only eight general crime types deemed characteristic of frequent gang involvement in the Western Cape were recorded in this analysis. It was hoped that this would serve to distinguish areas affected differentially by gang activity to the greatest extent. These included:

(1) Murder, (2) Attempted Murder, (3) Possession of unlicensed firearm and ammunition, (4) Possession of / dealing in narcotics, (5) Assault, (6) Rape, (7) Armed robbery \& (8) Public violence.

(The Crime Information Management Centre, 1998: 1).

Additionally it is important to note that districts included in the analysis of Area B were also documented as deeply embedded in gang processes (Crime Information Management Centre, 1998).

This distinction in gang activity was substantiated by participants within the study, in which $65.83 \%$ of respondents in Area B indicated the common presence of gangs in their neighbourhoods, whilst only $18.19 \%$ of all individuals in Area A considered them of any importance. A graphic presentation of these responses proves enlightening and may be seen in Figure 1.

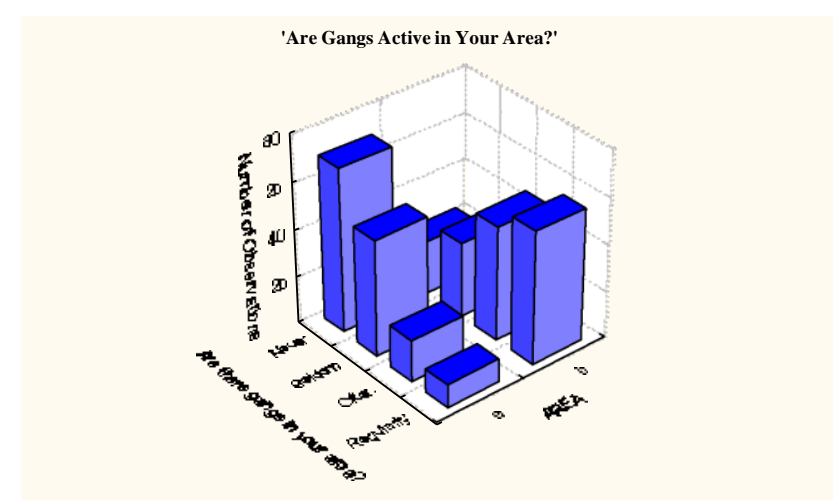

Figure 1. Participant responses surrounding gang activity in Area A and Area B.

It is informative to underline the socio-economic disadvantage plaguing communities of high gang activity. This is substantiated by Census 1996 unemployment figures which indicate that 92 persons per thousand find themselves unemployed in Area B whilst a mere 19 individuals in every thousand experience the same disadvantage within Area A. The inevitable deprivation caused as a result of high unemployment in areas in which gangs most frequently operate was given

Table 1. Number of Gang Related Crimes per 1000 persons within Area A and Area B.

\begin{tabular}{cccc}
\hline & Total No. Crimes & Total Population & No. of Crimes / 1000 Population \\
\hline Area A & 505 & 53852 & 9.4 \\
Area B & 8137 & 453039 & 18 \\
\hline
\end{tabular}


further substance through descriptive research results indicating significantly larger participant family size in Area B (7.5) as opposed to Area A (5).

Access to schools within these two areas was made possible through the 'Safer Schools Programme', a Western Cape Education Departmental initiative, dealing primarily with the problem of gangsterism in State schooling. In accordance with the distinction found to exist between these areas - with regard to gang related crime - researchers requested that three schools in each locale be made available as possible sites of study. Following approval of the proposed research by the Education Department all six schools agreed to participate. Area A included the suburbs of Newlands and Rondebosch while Area B incorporated both Hanover Park and Lansdowne.

In all 316 male pupils agreed to participate within the study in which 152 were drawn from Area A and 164 from Area B. Respondents ranged between 14 and 22 years, with a median score of 16 years, and a mean age of approximately 16.5. The age of pupils across areas was therefore found to be very similar. The centrality of age as a factor mediating the acquisition of masculinity is well illustrated by Jackson's (1990) refreshing autobiographical account of his early life, as well as Xaba (1997), in a discussion of returning political exiles in South Africa and their masculinity.

Respondents in both areas were predominantly seen to attend either grade 10 or 11 at school $(90.5 \%)$. This distribution emerges despite participants having attended a range of grades extending between 7 and 11. Slight variation manifests itself in the dominance of grade 11 pupils in Area A (66.89 \%) in contrast a small majority of grade 10 participants in Area B (51.53 $\%)$.

A total of $236(74.68 \%)$ participants were found to speak English as opposed to 80 (25.32 \%) Afrikaans speakers. More specifically, Area A comprised solely of English participants, differing somewhat from Area B in which 84 (51.22 \%) males spoke English whilst $80(48.78 \%)$ preferred the use of Afrikaans.

Importantly individuals in Area A and B differed markedly in terms of their ascribed 'race' and 'class'. Although some cross contact was evident in Area A, as a result of educational desegregation, most participants from this locale could be described as 'middle-class' and 'white'. In contrast those from Area B predominantly fell into the historical racial category of 'coloured' and lived within a 'working-class' environment. Despite being beyond the scope of the present study, the intersection of race; class; and gender, should not be ignored. This dynamic may fruitfully be explored in further studies surrounding masculinity in similar contexts.

Of some interest, given the nature of the study, participants were drawn from both co-educational facilities and male-only establishments. In this regard all respondents from Area B received educational instruction in a mixed gender environment whilst $99(65.13 \%)$ males in Area A originated from two single-sex institutions.

\section{Measuring instrument}

Participant negotiation of hegemonic masculinity across Area A and Area B was explored through the use of the Male Attitude Norm Inventory (MANI). Formulation of this device took form around two existing instruments - the Male Role Norms Inventory (Levant \& Fischer, 1996) and the Male Role Norms Scales (Thompson \& Pleck, 1987) - which were both similar in design. Important gender theorising also made a significant contribution to its derivation.
The Male Role Norms Inventory (Levant \& Fischer, 1996) also grew out of an attempt to measure conformity to normative Western cultural notions of masculinity, in which it was assumed that no single concept of masculinity was seen to exist, but rather recognised its differential construction across context. In this regard the device argued that a number of distinct traditional masculine norms were seen to operate in society that varied in the extent to which they were accepted or rejected by social groups. Seven sub-scales were developed to measure these norms:

(1) Avoidance of Femininity, (2) Rejection of Homosexuals, (3) Self-reliance, (4) Aggression, (5) Achievement / Status, (6) Attitudes towards Sex \& (7) Restrictive Emotionality.

The instrument appears to have offered theoretically meaningful differences in sub-scale scores across a variety of groups including those defined through gender, age, marital status and geographical location (Levant \& Fischer, 1996). It is clear that distinct parallels emerge between this and understanding of masculinity in the present study.

Research conducted by Thompson and Pleck (1987) investigating male attitudes toward traditional sex role demands - through the use of the Male Role Norms Scales - also made a large contribution to the formulation of MANI. This study usefully isolated three core dimensions of normative masculinity through factor analytic methods:

\section{(1) Status Norm, (2) Toughness Norm \& (3) Anti-femininity Norm}

It is informative to stress that the scalar items measuring these underlying norms were derived from normative societal "...beliefs that men should avoid doing anything feminine, conceal emotions and feelings that make men feel vulnerable, dedicate themselves to work and supporting a family, acquire skills that warrant respect and admiration, become mentally and physically tough, become self-reliant, and willing to take risks and engage in violence" (Thompson \& Pleck, 1987: 27). Although these items comprehensively reflect this conceptualisation of masculinity they fail to incorporate an anti-homosexual dimension and as such render the instrument vulnerable to criticism.

Consequently scalar items from both the Male Role Norms Inventory and the Male Role Norms Scales were incorporated within MANI as is highlighted within Table 4. In some cases they underwent slight alteration in order to make them more suitable to the cultural and linguistic flavour of the South African population. The complete measure encompassed the use of 40 belief statements congruent with dominant notions of masculinity. Participants were asked to indicate along a five-point response format whether they (A) strongly disagreed, (B) disagreed, (C) had no opinion, (D) agreed, or (E) strongly agreed with these male oriented items. A high item score was argued to signal an individuals agreement with normative conceptualisations of masculinity. These forty statements sought to operationalise twenty central concepts that were believed to be crucial in understanding dominant notions of masculinity. In order to attain discursive simplicity these concepts were arranged within five theoretically consistent categories. This is summarised in Table 2 .

A brief item analysis was undertaken as a means with which to ensure scale reliability. Although statistical investigation revealed that a number of individual items were skew in distribution, their removal was deemed inappropriate as sufficient variability in participant response emerged. Item means ranged from -0.968 to 1.244 and their standard deviations from 0.832 to 1.465 (Range from -2 to 2 ). 
Table 2. The five theoretically motivated categories included within the Male Attitude Norm Inventory and their underlying concepts.

\begin{tabular}{|c|c|c|c|c|}
\hline Anti-Femininity & Toughness & Individualism & Status & Homophobia \\
\hline Sexual Objectification. & $\begin{array}{c}\text { Tolerance for } \\
\text { Discomfort. }\end{array}$ & $\begin{array}{c}\text { Importance of } \\
\text { Activity. }\end{array}$ & Achievement Oriented. & $\begin{array}{c}\text { Homophobic } \\
\text { Ostracism. }\end{array}$ \\
\hline Anti-feminine Practice. & Emotional Detachment. & $\begin{array}{c}\text { Level-headed } \\
\text { Behaviour. }\end{array}$ & Career Oriented. & Homophobic Violence. \\
\hline Male Sexual Prowess. & Self-Containment. & Importance of & Resource & Homosexual Behaviour. \\
& & Independence. & Oriented. & Heterosexual Self- \\
& & Interpersonal & Power & Oriented. \\
\hline Disparagement of Women. & Physical Endurance. & & & \\
& & Dominance. & & \\
\hline
\end{tabular}

Lastly, the questionnaire appeared in both an English and Afrikaans form having been translated from the former into the latter. Consistency between these two information-gathering instruments was assured through the technique of backtranslation in which only a mere nine translation errors were in need of correction. Although it is important to stress that no translation should be seen to provide faultless equivalency between research instruments - as languages are never perfectly commensurate - the procedure did serve to eliminate the most glaring fractures between the two alternative versions.

\section{Qualitative method}

Qualitative methods were made use of in an attempt to render rich and descriptive data that is otherwise neglected in a purely quantitative endeavour. This was achieved through a number of open-ended questions presented within Section B of the questionnaire. Questions sought to elicit demographic data as well as information concerning gang activity. That is to say they probed whether gangs were active in participant schools, whether respondents had ever been gang members, their motivation for joining gangs, and a space for additional comments.

\section{Procedure}

The research questionnaire was administered to respondents during the course of a normal school day during September 1999. Groups of pupils in every school were asked to participate in the study, indicating their preference for either an English or Afrikaans questionnaire, which they were requested to complete without communicating with each other. Questionnaire completion took no longer than twenty minutes thereby limiting its intrusiveness on the everyday functioning of school life.

The questionnaire consisted of two sections. Section A required pupils to respond to the forty closed-ended questions included within the Male Attitude Norm Inventory. A brief introductory statement stressed that there were no right or wrong answers, merely opinions. Each individual was asked to express their feelings about these male oriented comments by indicating either their agreement or disagreement along a five-point response format. Section $B$ sought to elicit demographic information from respondents through the use of both open- and closed-ended questions.

The first author, together with the help of an assistant, personally conducted the survey in four schools. This enabled participants to seek direct clarification surrounding what was required of them, and in a few instances, explanation concerning questions that seemed unclear. Furthermore the researchers' presence enable them to stress the independence of the study from school structures, an association that might otherwise have restrained participants from answering sensitive questions in an honest fashion. Once all questionnaires had been returned the researchers briefly described the nature of the research initiative, highlighting the variable construction of masculinity across group context. Participants were also encouraged to ask additional questions concerning the study. The remaining two schools - one in each area - chose to administer the questionnaire without the researchers' presence.

All respondents were made aware of specific ethical considerations, appearing on the title cover of the questionnaire, stressing their anonymity and the confidentiality of data.

\section{Results}

\section{Descriptive results}

Descriptive data obtained through the use of the questionnaire served to validate sampling procedures seeking to obtain participants from locales differing markedly in their exposure to gang activity. A surprising 89 (60.96\%) respondents in Area A specified having knowledge of individuals belonging to gangs, contrasting only slightly with pupils in Area B, of which 125 $(78.13 \%)$ indicated their familiarity with gang members. Although these results seem to imply high participant association with gangs in both areas, the extent of participant exposure to gang activities across locales appeared distinctly different once the relational proximity between gang members and respondents was considered, well illustrated in Table 3.

Table 3. The relational proximity between gang members and participants in Area A \& Area B.

\begin{tabular}{|c|c|c|c|c|c|}
\hline \multicolumn{6}{|c|}{ Who do you know that belongs to a gang? } \\
\hline & Acquaintance & Friends & Family & Other & Row Totals \\
\hline Area A & 45 & 29 & 6 & 10 & 90 \\
\hline Column \% & $78.95 \%$ & $31.18 \%$ & $21.43 \%$ & $20.83 \%$ & \\
\hline Area B & 12 & 64 & 22 & 38 & 136 \\
\hline Column \% & $21.05 \%$ & $68.82 \%$ & $78.57 \%$ & $79.17 \%$ & \\
\hline
\end{tabular}


Clearly a greater number of individuals in Area B appeared to have close relations with gang members than did pupils originating from schools in Area A. Of all participants indicating their knowledge of gangsters, $78.9 \%$ in Area A underlined their status as mere acquaintances in contrast to a mere $21 \%$ in Area B, whilst only $31.1 \%$ in the former site noted having friends involved in gang activity as opposed to $68.8 \%$ in the latter location. Although no attempt was made to explore participant understanding of the term 'gang', it is worthwhile to note that it may have been defined differently by individuals in each area, perhaps more loosely by those in Area A. These findings served to enhance understanding surrounding the differential impact gang processes were found to have on young males attending school in each of the areas included in the study.

Results concerning participant gang membership also proved enlightening. In this respect only 9 (6.08\%) individuals in Area A admitted ever having been associated with gangs, whereas 31 $(19.38 \%)$ pupils in Area B stressed their once or continued active membership within gang structures. It is likely that many of the gangs mentioned in Area A differed substantially from those named in Area B, in both structure and purpose, given the large socio-economic differences evident between these two areas. Crime statistics - referred to above - would alone suggest the greater involvement of Area B gangs in a range of criminal activity. Interestingly participants freely provided the names of gangs to which they had been, or were presently affiliated, rendering information leading to the identification of a substantial 33 separate group labels.

The mean age at which individuals were noted to have first joined gangs held consistently across both areas at 13.5 years. Similarly the age range of this membership also remained largely congruent between research sites: roughly between 6 and 17 years.

In sum these descriptive statistics illustrated the fact that participants from the two locales, isolated in the research initiative, differed substantially in the extent to which they were exposed to gang activity.

\section{Statistical analyses}

The five theoretically motivated categories included within the Male Attitude Norm Inventory served as an initial focus of exploration. Through the use of principal factor analysis five factors were extracted in order to determine whether a similar configuration emerged through a priori analytic procedures. However following an orthogonal varimax factor rotation the resultant structure proved substantially different from these theoretically derived groupings. Additionally the fifth factor identified failed to meet traditional eigenvalue extraction criteria (i.e. $\geq 1.00$ ).

In accordance with the gender theorising adopted in this investigation, a factor analytic operation incorporating all participant responses was deemed the next most suitable undertaking. That is to say the theoretical foundation of the research initiative, suggesting the continual negotiation of masculinity over time and space with reference to its ascendant societal conceptualisation, indicated that an investigation surrounding dominant notions of masculinity was required. This differed somewhat from an alternative comparative approach that may have explored masculine interpretation between the two research sites by means of separate factor analytic investigation. Rather it was hoped that an exploratory inquiry of the former kind would yield a theoretically meaningful factor structure serving to simplify understanding surrounding hegemonic notions of masculinity held across groups within the study. It was argued that this solution would serve as a theoretically sound basis from which to delve deeper into variable masculine understanding between participant groups.

Once again principal factor analysis provided a means with which to examine the underlying factor structure of items incorporated within the Male Attitude Norm Inventory. Factor extraction was based on an eigenvalue of $\geq 1.00$, producing four factors, which after orthogonal varimax rotation accounted for $28.9 \%$ of total item variance. Only items with a factor loading of $\geq 0.400$ were retained in order to ensure powerful simplicity. Nevertheless the interpretability of the fourth factor proved problematic as only a single item was found to load substantively. The same procedure was reinitiated in an effort to explore the utility of a three, as opposed to a four factor model. After orthogonal varimax rotation the emergent factor structure was found to account for $26.36 \%$ of total item variance. These results were considered to be theoretically meaningful and provided a platform facilitating deeper inquiry into the way in which participants structured their understanding of masculinity. This three-factor solution may be seen in Table 4 .

Items loading substantively on Factor 1 were seen to reflect the belief that men should present themselves as physically, emotionally and psychologically hardy. Interestingly behaviour seen to enhance the display of this hardiness, in particular actions undertaken by men to distance themselves from the supposedly 'weak femininity' of women and homosexual males, appeared positively related to this apparent need to assert 'solidity' of character. As such this Factor was best understood as encompassing notions surrounding the importance of male toughness, in which all eleven items having a substantive loading of $\geq 0.400$ were included to form a sub-scale measure. In this regard anti-homosexual belief appeared related to the need to reinforce manly characteristics of toughness rather than existing as a defining element of masculinity itself. The toughness sub-scale was found to have good reliability demonstrated in a Cronbach's Alpha of 0.822.

The second Factor unambiguously stressed the importance of success in defining masculinity, in which men were expected to assume positions of leadership, presumably related to the fulfilment of status requirements. Consequently the term success was seen to describe the emphases embedded within this Factor. A mere three items were incorporated to form a success sub-scale, in which loading was once again considered substantive only at $\geq 0.400$. Due to the low number of items included in this sub-scale poor internal consistency unsurprisingly emerged, seen in a Cronbach's Alpha of 0.460 .

The relationship between items loading substantively on Factor 3 was of a more complex nature. In essence these were observed to interact so as to highlight the centrality given to male mastery over their lived environment. Not only did this illuminate participant belief surrounding the necessity of male control over their own lives, but the lives of other individuals as well, specifically women. It was found that item 34 negatively related to all other items loading on this Factor. In this regard it could be postulated that males supporting direct control of over women would be less likely to endorse indirect methods of domination. That is to say males supporting direct measures of oppression (e.g. item 22) may not endorse indirect exercise of control over females (i.e. item 34). Accordingly Factor 3 was argued to epitomise the primacy afforded notions of male control by participants in understanding masculinity. Nine items substantively at $\geq 0.400$ comprised what was called the control sub-scale, which after the reverse scoring of item 34 , rendered a high reliability seen in a Cronbach's Alpha of 0.778 .

As previously alluded to, critics may argue that a factor analytic exploration of individual responses in each of the two areas 
Table 4. The three-factor analytic solution of Inventory items.

\begin{tabular}{|c|c|c|c|c|}
\hline & Abbreviated Item Content & Factor 1 & Factor 2 & Factor3 \\
\hline $\begin{array}{l}1+ \\
2{ }^{*} \\
3 \\
4 \\
5^{*} \\
6 \\
7^{*} \\
8 \\
9 \\
10 \\
11 \text { * } \\
12 * \\
13 * \\
14 \\
15 \\
16 \\
17 \\
18 \text { * } \\
19 \\
20 \\
21+ \\
22 \\
23 \\
24 \\
25 \\
26 \\
27 \\
28 \\
29 \\
30 \\
31 \\
32 * \\
33 \\
34 \\
35+ \\
36+ \\
37 \\
38 \\
39+ \\
40 \\
\text { * }\end{array}$ & $\begin{array}{l}\text { A man should prefer sports to feminine activities. } \\
\text { It is embarrassing for men to have a woman's job. } \\
\text { Women are emotional in difficult situations. } \\
\text { Women do not understand money matters. } \\
\text { Men should not show pain. } \\
\text { The man's duty is to remain calm. } \\
\text { Men who cry in public are weak. } \\
\text { Men should never rely on others. } \\
\text { Men should keep their worries to themselves. } \\
\text { Men should hide feeling frightened. } \\
\text { To be a man you need to be tough. } \\
\text { The use of guns is sometimes necessary. } \\
\text { It is natural for men to enjoy taking risks. } \\
\text { It is admirable for a man to take the lead. } \\
\text { Men should think carefully and logically. } \\
\text { Men should remain calm in bad situations. } \\
\text { Men try to get women to have sex with them. } \\
\text { Men who are sure of themselves are respected. } \\
\text { A man should be responsible for his own success. } \\
\text { Gay men should be beaten-up. } \\
\text { A man should make all the decisions in the family } \\
\text { Women should do as men tell them to. } \\
\text { Men should know more about sex than women. } \\
\text { Men who are competitive are successful in life. } \\
\text { Men should be determined to do well. } \\
\text { Men should have jobs that earn them respect. } \\
\text { A man should be successful in his job. } \\
\text { Gay men should not be allowed to join the army. } \\
\text { A man's car tells a lot about how successful he is. } \\
\text { A man is successful if he makes a lot of money. } \\
\text { Men deserve the respect of their wife and children. } \\
\text { Men should be respected and admired by everyone } \\
\text { Fathers should be embarrassed if their son is gay. } \\
\text { 'Real' men discuss woman's 'looks' with friends. } \\
\text { 'Faggot' is one of the worst insults to a man. } \\
\text { Men should never kiss their fathers. } \\
\text { I think it is strange when men hug each other. } \\
\text { A real man should never pick flowers for himself. } \\
\text { Men should not wear bracelets. } \\
\text { Men can not have serious discussions with women. }\end{array}$ & $\begin{array}{l} \\
0.553 \\
\\
0.454 \\
0.412 \\
0.360 \\
0.367\end{array}$ & $\begin{array}{l}0.426 \\
0.555\end{array}$ & $\begin{array}{l}0.489 \\
0.421 \\
0.508 \\
-0.481 \\
\\
0.486\end{array}$ \\
\hline \multirow{2}{*}{40} & Eigenvalue & 7.316 & 1.841 & 1.387 \\
\hline & Percentage of Rotated Item Variance & $10.37 \%$ & $5.74 \%$ & $10.24 \%$ \\
\hline
\end{tabular}

+ Male Role Norms Inventory (Levant \& Fischer, 1996).

* Male Role Norms Scales (Thompson \& Pleck, 1987).

would have rendered a subtler form of comparative inquiry concerning masculine conceptualisation across groups. However apart from theoretical demands, statistical considerations also made this procedure unviable. In particular an investigation of this kind would have contravened the general requirement that there should be at least five times as many observations as there are variables. Although the ratio of variables to observations in Area A $(1: 3.75)$ and Area B (1: 3.93) was quite high, this infringement was still of some concern. Additionally the instability of data clearly emerged through random comparison of two sub-sample groups. In short this method sought to measure the consistency surrounding underlying factor structure through random assignment of participants to two groups and subsequently comparing their factor forms. This observed instability militated against the comparative exploration of factor structure between responses from each area. It is crucial to note that given time these limitations may have been overcome. Specifically a larger sample could have been obtained in order to overcome the area response deficit that served to render comparative factor analytic procedures problematic.

Nevertheless the three sub-scales - determined through the factor analytic technique described above - served as useful tools with which to explore significant differences in group support surrounding these pivotal axes of masculine understanding. In this regard three separate $t$-tests for independent samples were performed on raw participant response scores for each sub-scale in order to explore area variability in masculine conceptualisation. In all cases homogeneity of variance was confirmed through the use of Levene's test designed to probe this assumption. For convenience these results are presented in Table 5 and suggest the applicability of conducting standard t-test procedures.

T-test techniques were initially applied through the use of mean toughness sub-scale scores between participants from Area A and Area B. Findings suggest that there was strong significant

Table 5. Summary of results: Levene's test for homogeneity of variance.

\begin{tabular}{lccc}
\hline & Levene F $(\mathbf{1}, \mathbf{d f})$ & Df & Levene $(\mathbf{p})$ \\
\hline Toughness Sub-Scale & 0.654 & 299 & 0.419 \\
Success Sub-Scale & 6.286 & 312 & 0.013 \\
Control Sub-Scale & 1.010 & 307 & 0.316 \\
\hline
\end{tabular}


difference in the scores $(\mathrm{t}(299)=-5.781 ; \mathrm{p}<0.01)$. That is to say participants in Area $B(M=2.507)$ appeared to stress the importance of toughness in defining masculinity markedly more than individuals from Area A (-2.874).

Likewise a t-test exploration of difference between mean success sub-scale scores involving these two areas also revealed highly significant results $(\mathrm{t}(312)=-4.006 ; \mathrm{p}<0.01)$. Pupils in Area $\mathrm{B}(\mathrm{M}=3.006)$ were found to emphasise the centrality of success as a measure of masculinity to a greater extent than their counterparts in Area A (2.132).

Similarly the same procedure rendered powerfully significant findings when conducted in exploration of mean control subscale scores from each area $(\mathrm{t}(307)=-11.944 ; \mathrm{p}<0.01)$. In short Area B $(\mathrm{M}=2.704)$ respondents were found to demonstrate greater support surrounding notions of masculine control than did young men in Area A $(M=-4.107)$. Summary statistics of these analyses may be found in Table 6 . The range of scores for the 3 sub-scales prove useful: Toughness $(22 ;-22)$, Success $(6 ;-6) \&$ Control $(18 ;-18)$.

\section{Discursive analysis}

Qualitative comments drawn from Section B of the questionnaire served to bolster statistical analyses. Clear limitations surround the studies primary use of statistical analysis. In particular, quantitative techniques served to homogenise participant response under broad trends, bleaching colourfu discourses other than those conforming to hegemonic masculine ideology. As such criticism concerning the research initiatives neglect to investigate 'voices of protest' - against dominant understanding of masculinity - may well be justified. This emerged clearly in a number of passionate comments made by participants in space provided at the end of the questionnaire. This commentary frequently questioned hegemonic notions of male dominance:

"I love females and they should be treated the same as anyone else" (Participant 208 - Area A).

At times individuals in both areas also openly engaged with normative heterosexual societal prescription in which they questioned its validity as a definitive characteristic of 'true' masculinity:

"Ek voel ' $n$ regte man wat vriende kan wees met homoseksvele en nie omgee wat mense daaroor sê nie" (Participant 205: Area B).
'I feel that a real man is a person who can be friendly with homosexuals and does not care what other people say about this' (Authors' translation).

However the power of normative demand regularly continued to manifest itself in many cases in which individuals found themselves unable to completely renounce hegemonic standards, well illustrated in:

"I am not gay, but if I were to turn out gay it would not upset me, because I don't find anything wrong with homosexuality" (Participant 260: Area A emphasis added).

Additionally young men within the study did at times reject traditional emphasis on male toughness, in some instances reformulating 'real' masculinity as encompassing emotionality:

"Ek persoonlik voel ' $\mathrm{n}$ man is allenlik " $\mathrm{n}$ ware man as hy wys wie hy regtig is, en sy ware emosies na vore bring, al is dit war ook al!!!” (Participant 203: Area B).

'I personally feel that a man is a real man when he shows who he really is, and displays his emotions, no matter what' (Authors' translation)

Nevertheless individual challenges to dominant masculine understanding revolving around notions of toughness were frequently followed by statements excusing their 'momentary' resistance to its hegemonic form:

"Because some men may do women's jobs or show their feelings more than others - doesn't mean that they are less of a man! But seriously men do rule over women" (Participant 72: Area A emphasis added).

These comments served to highlight the multidimensional nature of masculine awareness in which vocal protest surrounding its dominant meaning was often found to exist. It is suggested that only through fully engaging in an analysis of participant discourse could the deficit in understanding wrought as a result of a predominantly quantitative research undertaking - be overcome. This point was alluded to by a number of pupils:

"The questions are pretty broad when answered so you can't exactly say how you feel about a certain aspect. You might agree with one thing but disagree with something else" (Participant 25: Area A).

Table 6. Descriptive summary: Toughness, Success and Control Sub-scales.

\begin{tabular}{llcc}
\hline SUB-SCALE & AREA A & AREA B \\
\hline Toughness & Mean & -2.874 & 2.507 \\
& Standard Deviation & 7.708 & 150 \\
& Valid N & 8.423 & 151 \\
Success & Mean & & 3.006 \\
& Standard Deviation & 2.132 & 1.788 \\
Valid N & & 2.077 & 162 \\
Control & Mean & 152 & 2.704 \\
& Standard Deviation & -4.107 & 5.093
\end{tabular}


Despite the evident limits in qualitative contribution toward a nuanced contextual understanding of masculinity the data did provide meaningful insight surrounding participant involvement within gang structures. In essence evidence supports the notion that an insistent gang culture provides young men with an arena in which to express the core demands of hegemonic masculinity outlined above.

In this respect the reported omnipresence of violence characterising gang activity may be seen as an attempt by individuals to assert their toughness. When asked - "What do these gangs do in your school?" - participants offered an array of responses underlining its centrality within gang culture. One participant provided a poignantly unambiguous answer:

Hulle..."Steek mes" (Participant 171: Area B).

They... 'Stab with knives' (Authors' translation).

Although violence seems to offer the most direct means through which gang members may display their toughness other common activities, including vandalism and peer intimidation, also appear to reinforce this factor.

An important difference in participant response arose between pupils situated in Area A and Area B when asked whether they wished to make any additional comments. That is to say respondents in Area B spontaneously mentioned on more than one occasion their wish for success:

"Ek wil suksesvol wees in die lewe"

(Participant 127: Area B).

'I want to be successful in life' (Authors' translation).

These statements grow in significance when it is noted that not a single individual in Area A noted their desire for success. It is reasonable to suggest that success for these participants remained an implicit assumption within their socio-structural location. However the desire for success noted by pupils in Area B was somewhat actualised through their participation in gangs, in which their identity as gang members afforded them some degree of enforced peer rank, as well as access to status enhancing resources:

"...hulle het "n lekker lewe met geld en draai by taxis" (Participant 184).

'...they had a great life with money and rides on taxis' (Authors' translation).

Clearly the intense want for success manifested by many of these young men played an integral role in their involvement in gang activity in which their participation principally revolved around the predominantly masculine need:

“To be recognised" (Participant 305: Area B).

The notion of control in an environment such as this served as a crucial source of masculine validation, providing the means by which young men were able to enforce their public "recognition", seen in the intimidation of both females and other males alike:

"They try to rule. But they cannot so they try to overpower" (Participant 315: Area B).

Furthermore the gendered nature of gang control emerges clearly in commentary made by pupils concerning motivational reasons for their involvement in gangs. The importance afforded access to females was obvious:

"The Islanders themselves are good friends and the dagga and wine (alcohol) was free and 'legal' in the area. So are the girl" (Participant 146: Area B emphasis added).

In this statement it is interesting to note that the "girl" appears at the end of a list of commodities that reportedly become more accessible through participation within gang structures. This objectified status of females is overt and finds firm reproduction in everyday gang behaviour:

"They rob the children and sometimes sexually harras the girls" (Participant 269: Area B emphasis added).

In sum although qualitative data made only a limited contribution toward a contextual understanding of masculinity it did nevertheless provide meaningful insight into male participation within gang structures. It supports the notion that gangs provide young men in deprived socio-economic settings with an alternative means with which to express toughness, success and control, identified as key features of hegemonic masculine understanding.

\section{Discussion}

An understanding of gender as a continually re-negotiated social practice, located in changing relations of structured power, aids an exploration of hegemonic masculine conceptualisation. In this sense masculine practice that fails to reflect normative behavioural demand is not always seen as an instant of 'protest', in which individuals dismiss the virtue of hegemonic values, but rather often reflect alternative means of achieving 'true' masculinity in contexts of disempowerment. Factor analytic procedures were seen to provide a means with which to explore the contextual structure of hegemonic masculinity across groups within the study. That is to say a mere re-application of an existing instrument of masculine measurement was considered inappropriate given theoretical imperatives stressing sociohistorical variability in its construction.

The three factors that emerged through the use of factor analytic techniques were clearly theoretically congruent; two displaying distinct similarities to dimensions encapsulated within existing instruments. That is to say the toughness and success orientations isolated within the current research undertaking appeared in like form within both the Male Role Norms Inventory (Levant \& Fischer, 1996) and the Male Role Norms Scales (Thompson \& Pleck, 1987). However the third factor, argued to reflect related constructs in terms of a male control orientation, was notably absent as a single dimension from both these prior tools of masculine measurement. It may be argued that the centrality afforded notions of male control in this study better summarises the array of alternative dimensions - other than 'toughness' and 'success' - previously propagated by these older devices. Furthermore it is important to note that the $26.36 \%$ of total item variance accounted for by these three extracted factors appeared in close approximation to the $28 \%$ total item variance explained by a similar factorial study conducted by Thompson and Pleck (1987).

This theoretically meaningful factor structure was seen to provide a firm base on which an exploration surrounding the contextual variability of masculinity between areas differentially embedded in gang culture could be built. Statistical analysis established that significant differences emerged in participant response between Area A and Area B, across all three sub-scale measurements, in which each outcome 
was also seen to hold theoretical logic. In many respects findings were in support of results offered by numerous previous investigations into subordinate masculinities. Young males in areas defined by pervasive gang activity were found to endorse participant notions of hegemonic masculinity, underlining the importance of toughness, success and control, to a greater degree than males removed from its daily occurrence. This may be interpreted in terms of an exaggerated form of masculinity argued frequently to develop in contexts of working-class powerlessness - as overstated rituals of gender appropriate practice - which through their collective performance lead to the accomplishment of manhood (Connell, 1995). From within this frame of reference gangs may indeed, as has previously been suggested, provide an ideal arena in which working-class boys are able to deal with their experience of structured powerlessness (Messerschmidt, 1997). Thus in this sense gang activity may be seen to play a pivotal role in the lives of many disempowered males, enabling them to collectively display manly attributes not otherwise available, and thereby reinforcing their status as 'true' men in agreement with hegemonic notions of masculinity.

Nevertheless clear methodological weaknesses emerge in the study's attempt to examine hegemonic masculinity. That is to say it fails to generate a comprehensive contextual understanding of masculinity before applying factor analytic techniques. As such little new knowledge concerning participant masculine conceptualisation, apart from the contextual structuring of traditionally recognised elements of dominant masculinity encapsulated by existing instruments of Western masculine measurement, finds original production. This suggests the need to conduct further in-depth exploration of contextual masculine understanding as opposed to simply applying an a priori model of hegemonic masculinity across groups included within the study.

\section{Acknowledgements}

Thanks go to Colin Tredoux for his help in statistical analysis, Chester Styles for his needed 'gatekeeping' support, Margot Luyt for her professional assistance in translation, and all the young men who agreed to take part in the study.

\section{References}

Bird, S.R. (1996). Welcome to the men's club. Gender and Society, 10, 120-132.

Brittan, A. (1989). Masculinity and power. Oxford: Basil Blackwell.

Carrigan, T., Connell, B. \& Lee, J. (1987). Toward a new sociology of masculinity. In H. Brod (Ed.), The making of masculinities (pp. 88-100). Boston: Allen and Unwin.

Coleman, W. (1990). Doing masculinity/ doing theory. In J. Hearn \& D. Morgan (Eds.), Men, masculinities \& social theory (pp. 170-199). London: Unwin Hyman.

Collier, R. (1998). Men, crime and criminology. London: Sage Publications.

Connell, R.W. (1987). Gender and power. Stanford, Calif.: Stanford University Press.

Connell, R.W. (1990). An iron man. In M.A. Messner \& D.F. Sabo (Eds.), Sport, men, and the gender order (pp.83-95). Champaign: Human Kinetics Books.

Connell, R.W. (1995). Masculinities. Cambridge: Polity Press.

Crime Information Centre (1998). The Western Cape Province crime report. South Africa.

Daba, L. (1991). Gangsterism in schools in black residential areas. South Africa: South African Institute of Race Relations.

Decker, S.H. \& van Winkle, B. (1996). Life in the gang. New York: Cambridge University Press.

Douglas-Hamilton, D. (1995). Warriors of the "Ghetto". South Africa: Institute of Criminology, University of Cape Town. du Pisani, J.A. (1997). Progression in perceptions of masculinity among the Afrikaans community, 1935-1995. Paper presented at the Colloquium on Masculinities in South Africa, Durban.

Edley, N. \& Wetherell, M. (1996). Masculinity, power and identity. In M. Mac an Ghaill (Ed.) Understanding masculinities (pp. 95-111). Buckingham: Open University Press.

Foster, D. \& Nel, E. (1991). Attitudes and related concepts. In D. Foster \& J. Louw-Potgieter (Eds.) Social psychology in South Africa (pp. 121-167). Johannesburg: Lexicon Publishers.

Gergen, K.J. \& Gergen, M.M. (1991). Towards reflexive methodology. In F. Steier (Ed.), Research and reflexivity (pp. 76-95). London: Sage Publications.

Griffin, C. \& Wetherell, M. (1992). Feminist psychology and the study of men and masculinity. Feminism and Psychology, 2, 133-168.

Hagedorn, J.M. (1998). Frat boys, bossmen, studs, and gentlemen. In L.H. Bowker (Ed.), Masculinities and violence (pp. 152-167). Thousand Oaks: Sage Publications.

Hearn, J. \& Collinson, D.L. (1994). Theorising unities and differences between men and between masculinities. In $\mathrm{H}$. Brod \& M. Kaufman (Eds.), Theorising masculinities (pp. 95-115). Thousand Oaks: Sage Publications.

Hemson, D. (1997). The embrace of comradeship. Paper presented at the Colloquium on Masculinities in South Africa, Durban.

hooks, b. (1995). Comrades in struggle. In M.S. Kimmel \& M.A. Messner (Eds.), Men's lives. Boston: Allyn and Bacon.

Jackson, D. (1990). Unmasking masculinity. London: Unwin Hyman.

Joe, K.A. \& Chesney-Lind, M. (1995).”Just every mother's angel". Gender and Society, 9, 408-429.

Kinnes, I. (1995). Reclaiming the Cape Flats. Crime and Conflict, 2, 5-8.

Levant, R.F. \& Fischer, J. (1996). The Male Role Norms Inventory. In C.M. Davis, W.H. Yarber, R. Bauserman, G. Schreer \& S.L. Davis (Eds.), Sexuality-related measures. Thousand Oaks: Sage Publications.

Mamputa, G. (1991). Gangs on the Cape Flats. South Africa: South African Institute of Race Relations.

Messerschmidt, J.W. (1997). Crimes as structured action. Thousand Oaks: Sage Publications.

Morrell, R. (1998). Of boys and men. Journal of Southern African Studies, 24, 605-630.

Pinnock, D. (1980a). Elsies River. Cape Town: University of Cape Town Press.

Pinnock, D. (1980b). From argie boys to skolly gangsters. Centre for African Studies, Africa Seminar, University of Cape Town

Pinnock, D. (1984). The brotherhoods: street gangs and state control in Cape Town. Cape Town: David Philip.

Pinnock, D. (1997). Gangs, rituals and rites of passage. Cape Town: African Sun Press.

Pyke, K.D. (1996). Class-based masculinities. Gender and Society, $10,527-549$.

Schärf, W. (1985). Street gangs, survival, and political consciousness in the eighties. South Africa: Centre for African Studies, University of Cape Town.

South African Police Service (1999). Semester Report 1/99. Pretoria: Crime Information Analysis Centre.

Swart, S. (1998). Republican masculinity and the 1914 rebellion. Journal of Southern African Studies, 24, 737-751.

Toch, H. (1998). Hypermasculinity and prison violence. In L.H. Bowker (Ed.), Masculinities and violence (pp. 168-178). Thousand Oaks: Sage Publications.

Thompson, E.H. \& Pleck, J.H. (1987). Reformulating the male role. In M.S. Kimmel (Ed.), Changing men (pp. 25-35). Newbury Park, Calif.: Sage Publications. 
West, C. \& Zimmerman, D.H. (1991). Doing gender. In J. Lorber \& S.A. Farrell (Eds.), The social construction of gender (pp. 13-37). Thousand Oaks: Sage Publications.

Wetherell, M. \& Griffin, C. (1991). Feminist psychology and the study of men and masculinity. Feminism and Psychology, 1, 361-391.

Xaba, T. (1997). Masculinity in a transitional society. Paper presented at the Colloquium on Masculinities in South Africa, Durban. 